\title{
Two Receptor Tyrosine Phosphatases of the LAR Family Are Expressed in the Developing Leech by Specific Central Neurons as well as Select Peripheral Neurons, Muscles, and Other Cells
}

\author{
Timothy R. Gershon, Michael W. Baker, Michael Nitabach, Peter Wu, and Eduardo R. Macagno \\ Department of Biological Sciences, Columbia University, New York, New York 10027
}

Receptor protein tyrosine phosphatases (rPTPs) are thought to play a crucial role in neuronal development, particularly in pathfinding by growing processes. We have cloned and sequenced two Hirudo medicinalis rPTPs that are homologous to the Drosophila and vertebrate rPTPs of the Leukocyte common antigen-related (LAR) subfamily. These Hirudo rPTPs, HmLAR1 and HmLAR2, are products of different, homologous genes, both containing two tandem intracellular phosphatase domains and ectodomains with three tandem Ig domains and different numbers of tandem fibronectin type III (FIII) domains. They are expressed in distinct patterns during embryogenesis. HmLAR1 mRNA is expressed by a subset of central and peripheral neurons and by several peripheral muscular structures, whereas HmLAR2 mRNA is expressed by a different subset of central neurons and by the peripheral, neuron-like Comb cells. HmLAR1 and HmLAR2 proteins are located on the neurites of central neurons. In addition, HmLAR2 is expressed on the cell body, processes, and growth cones of the Comb cells. Because of their CAM-like ectodomains and homology to proteins known to be involved in pathfinding and because they are expressed by different subsets of neurons, we hypothesize that HmLAR1 and HmLAR2 participate in navigational decisions that distinguish the sets of neurons that express them. Furthermore, we hypothesize that HmLAR2 is also involved in setting up the highly regular array of parallel processes established by the Comb cells. Lastly, we propose that the HmLAR1 ectodomain on peripheral muscle cells plays a role in target recognition via interactions with neuronal receptors, which might include HmLAR1 or HmLAR2.

Key words: receptor tyrosine phosphatases; neuronal development; muscle development; central neurons; peripheral neurons; Hirudo medicinalis
Neurons establish complex arbors as they grow and generate their adult patterns of synaptic connections. In many invertebrates, including leeches, these arbors are often both highly distinctive, such that one can distinguish one neuron from another by its branching pattern, and yet highly stereotyped, such that one can identify the same neuron in animal after animal. Neuronal development therefore establishes complexity with fidelity. An essential aspect of how a developing embryo accomplishes this is by adopting a modular approach. An individual neuron is not required to carry, at its growing tip, information about where every turn or branch should be located. Rather, information is distributed throughout the tissues of the embryo in the form of extracellular signaling molecules. The task of the growing neurite and growth cone, therefore, is to recognize cues that it finds in its microenvironment and to respond to them appropriately.

Directional guidance information is provided to the developing neuron by a great variety of molecules, including soluble small molecules such as acetylcholine (Zheng et al., 1994), soluble proteins such as netrins (Serafini et al., 1994; Colamarino and Tessier-Lavigne, 1995), and substrate-bound proteins such as cell adhesion molecule (CAM)-like proteins (Chiba and Keshishian, 1995) and Eph receptor ligands (Tessier-Lavigne, 1995). Interest-

\footnotetext{
Received Oct. 23, 1997; revised Jan. 30, 1998; accepted Feb. 2, 1998.

This work was supported by grants from the National Science Foundation and the National Institutes of Health.

The complete neucleotide sequences of HmLAR1 and HmLAR2 are registered with GenBank under the accession numbers AF017084 and AF017083, respectively.

Correspondence should be addressed to Dr. Eduardo R. Macagno, 1011 Fairchild Center, MC 2442, Columbia University, New York, NY 10027.

Copyright (C) 1998 Society for Neuroscience $0270-6474 / 98 / 182991-12 \$ 05.00 / 0$
}

ingly, there is evidence that the CAM-like guidance cues and CAM-like receptors may interact with each other (Stoeckli et al., 1997).

Guidance cue receptors must not only distinguish the signals that are relevant but must also transduce this interaction into internal signals that control process extension. Accumulating evidence implicates tyrosine phosphorylation of growth cone proteins in mediating the transduction of guidance cue recognition (Wu and Goldberg, 1993; Wu et al., 1996). Some guidance cue receptors, including the Eph receptors, have intracellular kinase domains known to modulate protein tyrosine phosphorylation (Tessier-Lavigne, 1995). The receptor protein tyrosine phophatases (rPTPs) are a family of transmembrane proteins that also have phosphotyrosine-modulating intracellular domains (Streuli et al., 1989). Several rPTPs have been implicated in neurite pathfinding (Stoker et al., 1995; Desai et al., 1996; Krueger et al., 1996). As yet, however, no ligands have been found for any rPTPs, and a receptor function for the rPTPs is inferred from circumstantial evidence.

The typical rPTP structure suggests a protein that transduces extracellular cues; a CAM-like ectodomain is united with an intracellular domain with enzymatic activity (Streuli et al., 1989). The protein tyrosine phosphatase activity of at least one rPTP intracellular domain has been demonstrated in vitro (Krueger et al., 1990), whereas the ability of the ectodomains of other rPTPs to mediate intercellular adhesion has been shown in insect cells (Brady-Kalnay et al., 1993) and mammalian cells (Sap et al., 1994). The ectodomains of the rPTPs, furthermore, have significant homology to known CAM-like guidance cue receptors, including axonin-1. From this evidence, it seems that rPTPs are 
receptors that transduce specific recognition of CAM-like cues into changes in tyrosine phosphorylation states of growth cone proteins.

Analyses of Drosophila loss-of-function mutants have provided the first direct evidence that rPTPs are involved in guiding growing processes (Desai et al., 1996, 1997; Krueger et al., 1996). The mechanisms through which the Drosophila rPTPs exert guidance effects, however, remain to be elucidated. An involvement of the rPTP leukocyte common antigen-related (LAR) in mammalian neuronal development has also been suggested by recent findings using LAR-deficient transgenic mice that show marked cholinergic neuronal atrophy (Yeo et al., 1997), possibly related to a perturbed neurotrophin signaling response (Yang et al., 1997).

To gain further insight into how receptor tyrosine phosphatases direct process outgrowth, we have sought Hirudo medicinalis rPTPs. H. medicinalis is a species with relatively large, slowly developing embryos. In this system we can resolve and observe individual neurons, processes, and growth cones in vivo. Although genetics analysis is not practicable, other methods of perturbation and observation are available. Here we report the sequence, expression, and protein localization pattern of two leech homologs of the mammalian rPTP LAR which we have called HmLAR1 and HmLAR2. These related proteins are the products of two distinct genes and are expressed throughout embryogenesis by different subsets of central and peripheral neurons. Interestingly, HmLAR1 is also expressed by specific nonneuronal peripheral cells, including certain muscle cells, suggesting functions beyond directing process outgrowth for rPTPs.

\section{MATERIALS AND METHODS}

\section{Molecular cloning}

PCR cloning and library screening. PCR was performed with the following degenerate primers using an oligo-dT-primed Hirudo medicinalis embryonic $\lambda$ ZAP cDNA library, generously provided by Dr. James Boulter (Salk Institute, La Jolla, CA), as template: sense, 5'-AA(A/G)TG(T/ C) GA(T/C)CA(A/G)TA(T/C)TGG-3'; antisense, 5'-NCCNGCN(G/ C) $(\mathrm{A} / \mathrm{T})(\mathrm{A} / \mathrm{G}) \mathrm{CA}(\mathrm{A} / \mathrm{G}) \mathrm{TG}-3^{\prime}$. These primers correspond to the amino acid sequences KCDQYW and HCSAG, respectively. PCR products were cloned and sequenced, and those clones that seemed to be related to LAR PTP catalytic domains were used as probes to screen the same library. This yielded cDNA clones corresponding to the HmLAR1 and HmLAR2 intracellular domains. These clones were then used to screen a random-primed cDNA, generously provided by Dr. R. Allen (Salk Institute, La Jolla, CA). This library was repeatedly screened until clones encompassing the entire coding region were obtained. For both HmLAR1 and HmLAR2, the 5'-end of the coding region was determined by finding the most $5^{\prime}$-methionine codon not followed by in-frame stop codons.

Sequencing and sequence analysis. Clones isolated from the cDNA library were sequenced in part by hand, using the Sequenase 2.0 DNA Sequencing kit (United States Biochemicals, Cleveland, $\mathrm{OH}$ ), and in part by automated sequencing. In each case, oligonucleotides coding for a previously determined HmLAR sequence were used as primers in the sequencing reactions. Newly determined sequence was then used to design new sets of primers that were in turn used in new sequencing reactions. This protocol was repeated until the sequences of the entire coding regions of both HmLARs were determined.

To assemble data from many sequencing runs, we had to perform a great deal of sequence analysis, including conceptual translation, local comparison, and comparison with protein and nucleotide data bases. The tasks were accomplished on a Sun Microsystems computer using the Genetics Computer Group (GCG) software package. In addition, suggested evolutionary relationships were derived using GCG software and using the PAUP 3.1 program (Swofford, 1994) for Macintosh computers.

The fibronectin type III (FNIII) repeats in the extracellular domains were identified based on an analysis of the predicted amino acid consen- sus sequence described by Kornblihtt et al. (1985) and used by others to classify FNIII repeats (Tian et al., 1991; Bodden and Bixby, 1996).

In situ hybridization. In situ hybridizations were performed according to the methods of Nardelli-Haefliger and Shankland (1992). Briefly, single-stranded sense and antisense RNA probes containing digoxygenin (DIG)-labeled uridine were synthesized by in vitro transcription using linearized cDNA clones as a template. These probes were hybridized to fixed dissected embryos at various stages of development. Unbound probe was removed by treatment with RNase, and bound probe was detected using alkaline phosphatase (AP)-conjugated antibodies to DIG. These antibodies were visualized with the Genius AP detection kit (Boehringer Mannheim, Indianapolis, IN). Finally, preparations were dehydrated, mounted in Permount, and examined using bright-field and Nomarski optics.

\section{Antibody production}

Antigen preparation. To make antisera against the ectodomains of HmLAR1 and HmLAR2, we subcloned portions of cDNA clones into bacterial expression vectors. cDNA fragments encoding the entire HmLAR1 ectodomain or the first $1 \mathrm{~kb}$ of the HmLAR2 ectodomain were isolated using PCR with $p f u$ polymerase (Stratagene, La Jolla, CA). The HmLAR1 fragment was ligated into pET 3c and expressed in bacteria according to the methods of Studier et al. (1990). The HmLAR2 fragment was cloned into pGEX2t and expressed in bacteria as a GST fusion protein according to the methods of Ausubel et al. (1995).

Heterologously expressed HmLAR1 and HmLAR2 proteins were insoluble and were purified according to the methods of Harlow and Lane (1988). Briefly, insoluble matter from bacterial cultures was recovered by centrifugation after lysis and then solubilized with SDS and $\beta$-mercaptoethanol. Fractions thus solubilized were run on large polyacrylamide gels, and proteins were visualized by $\mathrm{CuCl}_{2}$ negative staining. Appropriate bands of protein were cut out, and the protein was then electroeluted using an Elutrap device (Schleicher \& Schuell, Keene, NH) according to the instructions of the manufacturer. Purified protein was then quantitated by the Bradford reagent (Bio-Rad, Hercules, CA) method.

Antigen injection. Animals were maintained, injected with antigen, and bled by HTI Bioproducts. The HmLAR1 antigen was injected into three rabbits according to the proprietary "accelerated protocol" of HTI. An additional boost of antigen was added $\sim 1$ month after the completion of the protocol, and the animals were then exsanguinated. The HmLAR2 antigen was injected into three rats in three doses of $100 \mu \mathrm{g}, 2-3$ weeks apart. After 8 weeks, the animals were exsanguinated.

Affinity purification. Sera were affinity purified according to methods described by Harlow and Lane (1988). Embryonic leech and GSTproducing bacterial cell lysates, as well as heterologously expressed, gel-purified HmLAR1 and HmLAR2 antigens, were fixed to $1 \mathrm{ml}$ portions of cyanogen bromide-activated Sepharose beads (Pharmacia, Piscataway, NJ) according to the instructions of the manufacturer. These beads were then loaded into columns, and the columns were washed extensively with PBS. Antisera, filtered to $0.2 \mu \mathrm{m}$ and diluted $1: 10$, were passed first through the bacterial and leech columns and then through the appropriate HmLAR column. The leech and bacterial columns were intended to remove undesirable binding activities, whereas the HmLAR columns served to concentrate the appropriate antibodies. Antibodies were then eluted successively with acid and base, and their concentrations were determined approximately by measuring light absorbance at $280 \mathrm{~nm}$. The most concentrated fractions were pooled, dialyzed against PBS, and used in subsequent immunohistochemical techniques. All antisera were stabilized with the addition of sodium azide and bovine serum albumin (BSA) to a concentration of $10 \mathrm{mg} / \mathrm{ml}$.

Several assays for antibody specificity were performed. First, the affinity-purified HmLAR1 and HmLAR2 antibodies were found to label bacterial HmLAR1 and HmLAR2 fusion proteins, respectively, as assayed by immunoblots (data not shown). In addition, labeling with the antisera was compared to the results of in situ hybridization with corresponding RNA probes for consistency. As a result of this analysis, the HmLAR1 affinity-purified antibody was found to label glial cells that were not labeled by in situ hybridization. Therefore, further purification was attempted to determine whether this labeling was artifactual or reflected the presence of real HmLAR1 protein within but not synthesized by these cells. Two 500 bp fragments were subcloned into pGEX2t, one encoding the $5^{\prime}$-most Ig subdomain and the other the $5^{\prime}$-most FNIII subdomain. These inserts were then expressed in Escherichia coli, and the resulting proteins were purified and used in place of the full-length 
HmLAR1 antigen for affinity purification. The HmLAR1 antibodies directed against the Ig or FNIII domains of HmLAR1 gave identical labeling results when used in immunohistochemistry and, most importantly, did not label the glia.

The affinity-purified HmLAR2 antibodies seemed to be specific for this antigen, because they labeled the same cells that were labeled by in situ hybridization in whole mounts of leech embryonic body wall (see Results). As a further control for specificity, labeling with this antiserum was compared to immunostaining with a different polyclonal antibody that had been raised against the intracellular phosphatase domain of HmLAR2 (Nitabach, 1995). Identical patterns of tissue staining in the body wall were observed, supporting the assertion of specific recognition of the HmLAR2 antigen (data not shown).

\section{Immunohistochemistry}

$H m L A R 1$. Embryos at various ages were dissected and fixed in $4 \%$ formaldehyde for $1 \mathrm{hr}$. Animals were then washed for 2 or more hours in PBS with $0.5 \%$ Triton X-100 (0.5\% PBT) and incubated in $0.5 \%$ PBT plus $2 \%$ normal goat serum (NGS) for $30 \mathrm{~min}$. Finally, primary antibodies were applied (diluted 1:10 in $0.5 \%$ PBT plus $2 \%$ NGS) overnight. The next day, preparations were washed with several changes of $0.5 \%$ PBT over 5 or more hours, after which goat anti-rabbit Cy-3-conjugated secondary antibodies, diluted 1:200 in 0.5\% PBT (Jackson ImmunoResearch, West Grove, PA), were applied overnight. Finally, preparations were washed extensively, mounted, and examined.

Before dissection, some animals were treated with brefeldin-A. The purpose of brefeldin-A treatment was to prevent protein secretion and thus to cause HmLAR1 ectodomain to build up in cells that express it. Brefeldin-A was initially solubilized in $100 \%$ ethanol and then diluted in $0.1 \%$ fast green solution to a concentration of $500 \mu \mathrm{g} / \mathrm{ml}$. Two microliters of this solution were then injected into embryos by the same technique described below for HmLAR2 antibody injection. Embryos were then transferred to artificial pond water (leech Instant Ocean solution) containing brefeldin-A at $10 \mu \mathrm{g} / \mu \mathrm{l}$ and were allowed to develop for $18-24 \mathrm{hr}$. Longer treatment in brefeldin-A was lethal.

HmLAR2. For HmLAR2 immunohistochemistry, essentially the same techniques were used as described above. In some experiments, however, Triton X-100 was omitted. In other experiments, antibodies to HmLAR2 were injected into live embryos 1 or $2 \mathrm{~d}$ before dissection and fixation. In these preparations, the primary antibody incubation was omitted, but Triton X-100 was applied with the secondary antibody. In addition, fluorescent secondary antibodies did not yield satisfactory staining. Instead, $10 \mathrm{~nm}$ colloidal gold-conjugated (Ted Pella) or peroxidaseconjugated (Cappel, Cochranville, PA) goat anti-rat secondary antibodies were used (diluted 1:40 or 1:100, respectively). The gold-conjugated antibodies were visualized using a commercial silver enhancement kit (Ted Pella) according to the instructions of the manufacturer. The peroxidase-conjugated secondary antibodies were visualized by treating the tissue with $0.03 \%$ diaminobenzidine (DAB) and $0.3 \%$ hydrogen peroxide in PBS until the staining was satisfactory. Some DAB-stained preparations were subsequently intensified according to the protocol of Vaney (1992). Background labeling by the immunohistochemistry procedures was assessed by excluding the primary antiserum from the protocols.

FMRFamide. Polyclonal antisera raised against the neuropeptide FMRFamide were used to colabel some preparations after HmLAR2 colloidal gold-silver immunohistochemistry. Two different antiFMRFamide sera (one generously provided by Dr. Robert Elde; one commercially available from Peninsula Laboratories) produced similar results. Antibodies were diluted 1:200 in $0.5 \%$ Triton X-100 in PBS and remained on the preparations overnight at room temperature. After several hours of washing, preparations were stained for $3 \mathrm{hr}$ with Cy-3-conjugated goat anti-rabbit secondary antibodies (Jackson ImmunoResearch) diluted 1:200 in $0.5 \%$ Triton X-100 in PBS. Finally, preparations were washed, mounted, and examined by bright-field and fluorescence microscopy.

\section{RESULTS}

\section{HmLAR1 and HmLAR2 are leech homologs of the rPTP LAR}

Using PCR with degenerate oligonucleotide primers, we sought to amplify a portion of the highly conserved intracellular catalytic domain of as yet unidentified leech LAR gene family members.
After cloning and sequencing the PCR products, we found that we had amplified fragments of the phosphatase domains of two clearly distinct LAR-like homologs. Using these fragments to initiate a repetitive screening of a cDNA library, we obtained full-length clones of HmLAR1 and overlapping clones of HmLAR2. The HmLAR1 transcript most heavily represented in the cDNA library contained a coding region of $\sim 4.5 \mathrm{~kb}$, whereas that of HmLAR2 contained $\sim 5.5 \mathrm{~kb}$ of coding sequence. The predicted extracellular regions of HmLAR1 and HmLAR2 show that both have an $\mathrm{N}$-terminal region resembling a signal sequence ( $\sim 30$ amino acids with predicted hydrophobicity), followed by three Ig domains and a region of reiterated FNIII domains that varies in length between the two genes, four domains for HmLAR1 and at least nine for HmLAR2. A comparison with domain III-7 of human FN (Kornblihtt et al., 1985) showed that three of the four designated FN III domains of HmLAR1 and all of the repeats for HmLAR2 shared the highly conserved tryptophan, tyrosine, leucine, and serine residues of most FN type III repeats. The fourth designated FNIII domain of HmLAR1 shared approximately half of these consensus residues but was nevertheless designated to be FNIII-like because of the presence of other shared residues found in it and all of the other designated FNIII domains of the two leech genes (data not shown). The putative transmembrane domain occurs at residues 775-803 for HmLAR1 and at 1378-1407 for HmLAR2, and two LARspecific phosphatase domains occur in tandem in the intracellular domain.

Sequence comparisons of the two HmLARs using the computer programs PAUP 3.1, which compares amino acid sequences by parsimony, and Divergence (GCG software package), which considers simple pairwise comparisons, reveal that (1) the two HmLARs are more like each other than they are like any of the other LAR family members and (2) Drosophila LAR, the only LAR family member identified in arthropods, is more similar to rat LAR than to either HmLAR1 or HmLAR2. The deduced amino acid sequences of HmLAR1 and HmLAR2 are shown in Figure 1.

\section{HmLAR1 mRNA is expressed by an initially small subset of central neurons that expands as development proceeds}

We analyzed the expression pattern of HmLAR1 by in situ hybridization at various stages of development, beginning with embryonic day 7 (E7). At this stage, the anteroposterior axis displays a temporal gradient of development in which the most posterior segments lag $\sim 1 \mathrm{~d}$ behind those most anterior (Fig. 2, compare $A, B)$. HmLAR1 mRNA is expressed at E7 by five pairs of neurons in each neuromere in the anterior two-thirds of the embryo, including the four neuromeres that will form the head ganglion and $\sim 15$ that will form the midbody segmental ganglia (Fig. $2 A, C-E$ ). Because the most posterior segments are representative of the state of the most anterior segments $1 \mathrm{~d}$ earlier, it may be inferred that HmLAR1 expression in the CNS probably begins during E6.

The expression of HmLAR1 mRNA was strongest in the more anterior ganglia at E7 (Fig. $2 A$ ), indicating that, at this time, expression levels in the central neurons are rising. The number of central neurons expressing HmLAR1 remained approximately the same until E9, after which there was a rapid increase in the number of cells expressing the message at detectable levels (Fig. $2 F-H)$. The increase leveled off after E10, and at E17, only 
HMLAR1 1 MNLPAGRAINTRYLATSEVMITCSLAYMVDHDDAPRITTAPRDQKVMEGK 50 HILLAR2 1 MKMLPTS-TLA-L--FKEGQSPG--IMIHRKSRP--VV.....-----N 45

51 IASFFCKASGNPAPEV. YWKRGWK. ESL. HDKNETKTSNMPHGSVLRVDP 97 46 M-T-W-GVV-K----MTWYHMNR-L--FTYQQSSR-I FTHHNL-----E- 95

98 TKWOKDETIIECVAESGIGHQAATATARLHIYRENEE. PKGFPRLLETPE 146 $96 \mathrm{~V}-. \mathrm{KR}--\mathrm{GRY}--\mathrm{E}-\mathrm{HN}-\mathrm{V}-$.VPDRVSFN-SV-TK-DPI-A---EI-VH-K 143 $\nabla$

147 MRSVEKDRNFILKCSATGDPEPSVYWLKDNIPVDMSDKRIQVLPGGSLSI 196 144 LG---RY-STVMA--GK-N---TFS----E--IEFTPV-ES-M-T-A-QL 193

197 RNGQGSDEGKYECVAENIHGTVHSFPASLYIRIRRVP PHFSVQIQNKEVP 246 194 L-STY-Y------I-E-S--VTN-QQ-T-VLKA--I-----ALPD-A--V 243 247 LGGSLNVTCVVGGAPMPHVRWKHGDIDLT. PENNI PIGKNVLRLEDVKOS 295 244 H-D.--L--TAS-S-E-F'IM-KRNNL--SHRS--HSH-TG-----GITE- 293

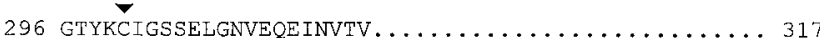
294 AN-T-HAI----TASHVVQ-K-NVLPKPPSSLWITEVSPNTVHLKWSPGN 343 294 ANI HAI $\Gamma_{\text {FNIII domain }}$

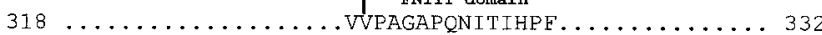
394 AVNKLGRSASSTPVDVVTGEL--GSE-P-VRAR-VSGTTVVVTMGRTNHC 443

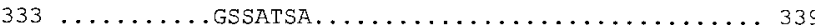
644 SSSLPSLPPPSS--SS--IVDGFNLYFSETKNFDDKSPHRSLNLTSDLRS 693

$340 \ldots \ldots$ KLQWNAPDIRIKQGDSTLYEVVYHLRQDONKEWSTNITEEFI 381 944 AVLGAHTIR-H-DP-VKKLRH-VIQM-----CESD-PGQDVMV-T--TSL 993

382 IFENLLPNSEYIFOIRAHTYKGPGPWSYQLPFKTPPFOFPNPPTDILIRR 431 994 VVDK-EADRS-T-IV--F-SA-GS--TNRVIKA-SSSTALPA-LN-RL-Q 1043

432 VHSTEMEVSWV. .. APTPLRGVSGYRIYYNEVALSDIDMWKFVDVDSPYT 478 1044 TSV-S----DELHGKN--.N-L-----SSTPNANL-K-SII-IGP . G 1090

479 TTLEISNLEPYSVYTVRVRAKYSDGS FGNLSETAYSNKLEDEHPEMVREF 528 1091 -SA-VHG-D-STT-S--I--RG---R--I--DQSSPTDWIMKIRKQFQVS 1140

529 QSQVLDSKT IVLQWKAPRKAGLSRYQIEYEGRKRVSSDHTGLEETVIDTK 578 1141 SAELTTPGPSYSSGRF---P-VL--KI--M-VRK.TR-FS-M-D-TV-PR 1189

579 KSEQVEKGAOSFRIENLLSNTLYSINITAKEIDGITGPPYQLRVETSPSD 628 1190 -EVTLQ-EER-RSLDE-M-R---TF--S-R----TW---TTIH---N, -E 1238

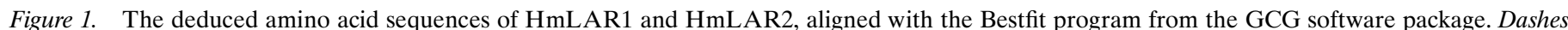

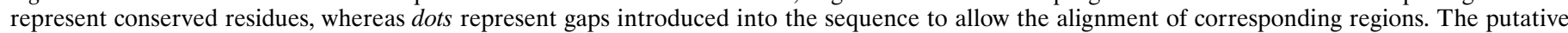

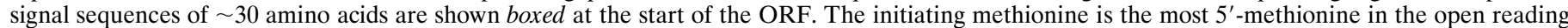

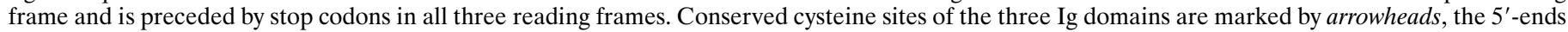

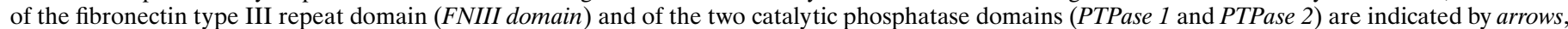
and the transmembrane domain is bracketed.

two or three additional pairs of neurons expressed HmLAR1 (Fig. 2I-K).

\section{HmLAR1 is also expressed by peripheral neurons}

Several peripheral neurons expressed HmLAR1. As early as E7, cells of the anterior root ganglia (ARG) and body wall were labeled by in situ hybridization. The HmLAR1-expressing body wall cells resemble in number, position, and developmental sequence a population of peripheral neurons identified and described by Stewart et al. (1985) using the monoclonal antibody Lan 3-6. In situ labeling of the body wall cells (Fig. 3A) and the ARG cells (Fig. $3 B$ ) persisted throughout development. Lastly, HmLAR1 was expressed by E25 by the nephridial nerve cells (Fig. $3 C$ ), a paired, segmentally iterated peripheral neuron identified by its morphology and soma position close to the nephridial pore and duct.

\section{HmLAR1 is also expressed in the periphery by muscle cells}

HmLAR1 was also expressed by a variety of peripheral muscle tissues. Starting at E7, HmLAR1 was expressed by cells lo-
629 PPVLEAPTLLRVTGDLLVVMRLSLFSVOPMYDNVOYYVVVPANERRGPE 678 1239 ETI-DP-SFI-PLS-QM-SL-VK. -AADVLGKVL--LIF---TEVA-TY- 1287

679 SVHIDELKGPHR. . . . DGWIASRFDGMLPREMNLGDGSRSAVGEFINHR 723 1288 FLKNS ISKNTQKPRCRG--LQVGLM-QTE--RLSW-MAGEPM . . T-STDP 1335

724 LRKDQIYKVFIRSIIPGSKFHFYVQIMSSSSPYSAPFSLDRLTMEIKGHP 773 $1336 \mathrm{FP}-\mathrm{GHN}-\mathrm{VAVL}-\mathrm{AVLGDN}-\mathrm{VI}-\ldots \ldots \ldots$.---K--FT-PAYL.CSWY- 1376 774 ISANEDLLWIVGPMCAAIVLILLVVLIII FNRNRNRENNSKRYLLPROPT 823 1377 TGRVWIY----A-I---V-----LI-V--IA-K-RVQDKN . . . IAAPTN 1422

824 KIMPSADLSIHPT . . DP. . VRRLQYQT'QAMACHPSIPISEFAAHVEQLKA 869 1423 -VLIP-GSEM--SFV--VD---M-F-SP--VN--P-RVEDL-T-L-A-R- 1472 870 CNCARTEF $\rightarrow$

$920 \mathrm{~L} \ldots . . \ldots \ldots$ EGISGSDYINANFMDGYRKSNAYIATQGPLPET FVDFW 958 1523 -PQASSTYHFPGQVVP-------L--E--Q-----n-MA--S---- 1572

959 RMVWE. QRVTT IVMMTKLEERGR IKCDQYWPNRGTEVYGPMHVTLVDVVEL1008 1573 -----R-.SPV-----------V------S--S-S-SLQ-N----I--1622

1009 ATYTLRTFIVTKTGQOERIEVKQFOFTAWPDHGVPEHPTALLMFHRRVRS 1058 1623 -T--M---QMSSEFNS-KR--RH--------Y-----AAP--L--EEGQV 1672

1059 EHTVDSGPMVVHCSAGVGRTGREIVVDRMLERALHEKTIDVYGHVTCLRA 1108

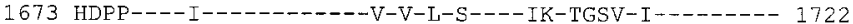

1109 QRNYMVQTEDQYIFVHDAILEGVTSGCTEVPARNLYAHMQKL . . MSLES 1155 $1723------------I-A--\cdots-A---N-------E-----L E P L T I T-1772$ 1156 GSN .....TLMEVEFRKLANIKTSSSOFASA PTPase 2 1773 Q-GHSTTI-GI-A-----SSG---L-S----N-SC--Q------V--.-T 1822

1202 SRVTLQLIRGVDGSDYINANF IDGYRYKKAYIATQGPLASTTEDFWRMLW 1251 1823 T--C--P-n----------S-------RR---------PD-V-----A-- 1872

1252 EHNSTIVVMLVKLREMGREKCLQYWPSERSARYQY FVVDPMVEYNMPOYI 1301

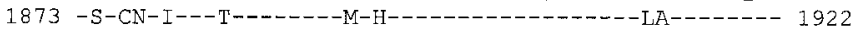

1302 LREFKVIDARDGQSRTIRQFOFWDWPEQGVEKSGEGFVDFIGQVHKTKEQ 1351 1923 --

1352 EGQDGPITVHCGAGVSRTGVFIALSVVLERMRYEGVVDLFOTVRLIRTOR 1401 1973 - - E---A---S---G------T--I------F--A--V----NV----- 2022

1402 PCCVKLRLQVQTPEDHYAFCYRAALEYLGSERHYAN 1437

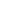



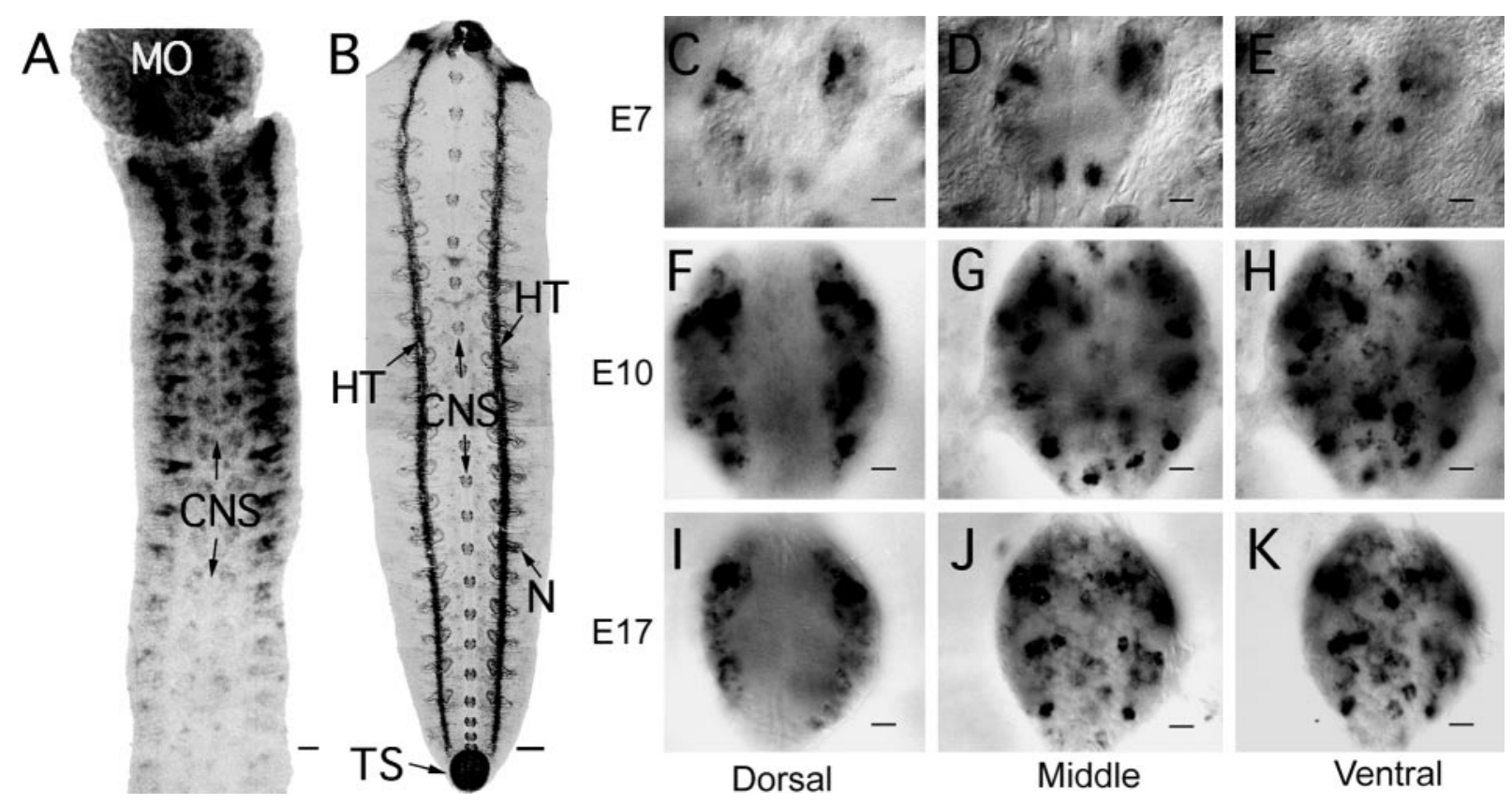

Figure 2. The number of central neurons that express HmLAR1 mRNA increases with the stage of development. Shown here is labeling using full-length HmLAR1 antisense probes of embryos at E7 and E10, as well as a series of images of individual midbody ganglia taken at three focal planes and from embryos at three different ages. Identical labeling was observed with probes transcribed from either intracellular or extracellular cDNA template, and no labeling was seen with sense RNA probes (data not shown). A, At E7, HmLAR1 is expressed in the CNS and in two flanking, stripe-like domains. Note that expression is highest in the more anterior, more developed segments. Staining of the cryptolarval mouth $(M O)$, a transient structure, is probably artifactual. $B$, At E10, the general pattern of HmLAR1 expression is preserved, and mature structures such as the heart tubes $(H T)$, nephridia $(N)$, and tail sucker $(T S)$ have developed. $C-E$, At E7, five pairs of central neurons labeled strongly, two pairs close together in the anterodorsal region of the ganglion $(C)$, one pair near the posterior margin, midway along the dorsoventral axis $(D)$, and two pairs near the ventral surface $(E)$. $F-H$, By E10, high levels of expression were observed in $\sim 12$ pairs of central neurons distributed throughout the ganglia. $I-K$, By E17, a few additional cells expressed HmLAR1, although the rate of increase was much less than was that between E7 and E10. Anterior is up. Scale bars, $10 \mu \mathrm{m}$.

\section{HmLAR1 protein is found along neurites within the CNS and in the periphery}

Antisera raised against the extracellular domain of HmLAR1 protein detected the protein on neurites (1) projecting across the ganglia through the anterior and posterior commissures, (2) projecting to adjacent ganglia through the interganglionic connective nerves, and (3) exiting the CNS through the anterior and posterior nerve roots and projecting along peripheral nerves (Fig. 4A-D). Antisera also labeled the heart tubes and dorsoventral muscles (Fig. 4D). Although sera were initially raised against the complete extracellular domain, they were affinity purified using only the three Ig domains or the two FNIII domains closest to the transmembrane domain. Sera were purified in this way to eliminate strong artifactual staining that was produced when the complete extracellular domain was used for affinity purification (see Materials and Methods). Sera purified against either fragment labeled the same structures in the animal (data not shown).

\section{HmLAR1 antisera label neuronal somata only if protein secretion is blocked}

The in situ hybridizations described above indicate that HmLAR1 is expressed at high levels by a discrete set of central neurons. Initially, however, antisera against the HmLAR1 ectodomain did not label the neuronal somata, making it difficult to compare the in situ hybridization and immunohistochemical labeling patterns. Poisoning protein secretion with the fungal toxin brefeldin-A (BA), however, effectively caused HmLAR1 to accumulate to immunohistochemically detectable levels in somata. Central neurons corresponding positionally to some, but not all, of the HmLAR1 mRNA-expressing cells labeled their somata (Fig. 4C) after treatment for $24 \mathrm{hr}$ with BA.

BA causes the Golgi apparatus to fuse with endoplasmic reticulum, preventing the export of normally secreted and cell surface molecules. To visualize HmLAR1 protein and to determine whether it was present in the same cells that were labeled by in situ hybridization, we found it necessary to treat embryos with brefeldin-A no less than $\sim 24 \mathrm{hr}$ before immunostaining. Brefeldin-A clearly sickened the embryos, causing their normal elongation to be severely restricted and killing embryos after 36-48 hr. When a variety of neurons were visualized by intracellular dye injection $24 \mathrm{hr}$ after brefeldin-A treatment, however, they maintained elaborate and apparently healthy morphologies (data not shown), indicating that the drug had not caused generalized disruption of the embryo within this period of exposure.

\section{HmLAR2 mRNA is expressed by a small number of central neurons and peripheral cells in a relatively stable pattern}

HmLAR2, like HmLAR1, was expressed as early as E7. In the CNS, four pairs of neurons were labeled at E7 (see Fig. 6A, $B$ ). Note that in these E7 preparations, a strong background signal was produced on the internal surface of the germinal plate where the membrane dividing the embryo from the yoke could not be dissected free. At E14, these same central neurons continued to express HmLAR2 (Fig. 5D,E), whereas another pair near the ventral surface of the ganglion was also labeled (Fig. 5C). Apart from the appearance of this last pair of cells, 

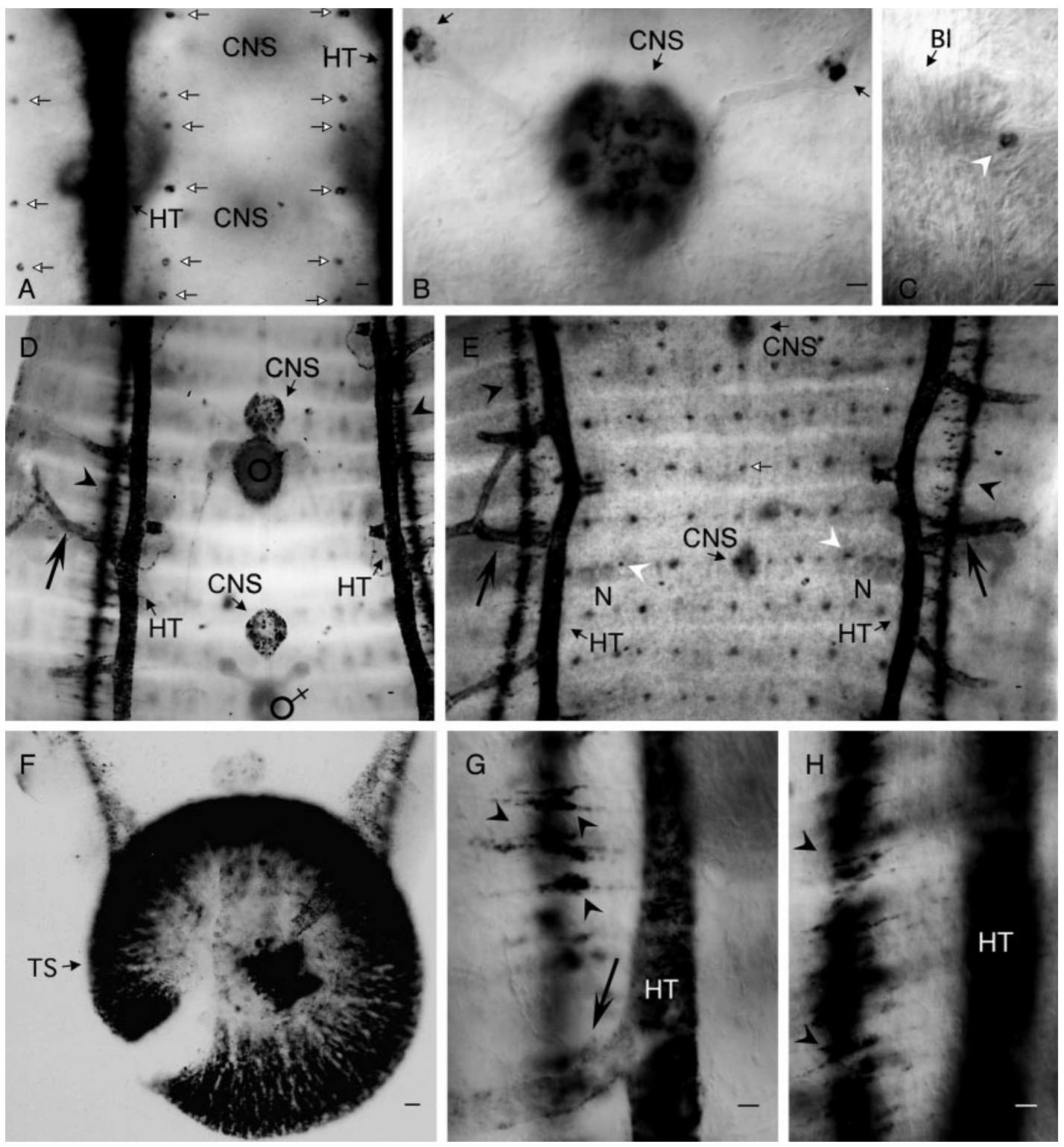

Figure 3. HmLAR1 mRNA can be detected in specific peripheral neurons and muscles by in situ hybridization. $A$, Approximately one and a half segments of an E10 preparation are shown. HmLAR1 expression was observed in two bilateral lines of cells (arrows) in the body wall, one of the groups aligned ventral to the heart tubes $(H T)$ and the other more lateral. From their positions, these cells are likely to be Lan 3-6-expressing peripheral neurons (see Results). Out-of-focus ganglia of the ventral nerve cord are noted by CNS. B, Labeled neurons are easily discernible (arrows) in the small anterior root ganglia (ARG) in this image from an E17 embryo. Nomarski optics were used to enhance the visualization of the root nerves of the midbody ganglion at the center as well as at the ARG. C, HmLAR1 was also expressed by the bilateral, segmentally iterated nephridial neuron (white arrowhead). In this image from an E25 embryo, the urinary bladder $(B l)$ was visualized using Nomarski optics. $D$, Low power view of the fifth and sixth body segments of an E17 embryo is shown. HmLAR1 was found to be expressed by two lateral bands of cells (arrowheads) corresponding to the dorsoventral muscles (see $G, H$ ), by the lateral $H T$ and the muscular portion of the secondary vasculature that connects to them (arrow), and by cells in the muscular portion of the male genitalia, probably the penile sheath (male symbol). In contrast, no HmLAR1 expression by cells of the female genitalia (female symbol) was detected. $E$, Image of approximately one and a half segments of an E25 preparation is shown. The number of HmLAR1-expressing cells in the body wall (white arrow) had increased significantly relative to that observed at E10 (compare with $A$ ). HmLAR1 was expressed late in embryogenesis by a regular array of cells on each annulus that appear to correspond to Lan 3-6-expressing sensory neurons. HmLAR1 expression by the dorsoventral muscles (black arrowheads), by the nephridial $(N)$ neurons (white arrowheads), and by the $H T$ and secondary vasculature (black arrows), as well as by the $C N S$ (out of focal plane), persisted at this late stage. $F$, The tail and posterior-most midbody segment of an E11 embryo are shown. HmLAR1 expression is evident in the muscle cells of the tail sucker $(T S)$. $G, H$, High magnification views of a lateral region of the body wall of an E17 embryo are shown. The HmLAR1-expressing cells of the medial $(G)$ or lateral $(H)$ groups of dorsoventral muscles are in focus and show a strong signal in the perinuclear domain and a weaker one more distally along the muscle fibers. The $H T$ is also clearly visible to the right; a muscular tributary $(G$, arrow) is also visible. Anterior is up. Scale bars, $10 \mu \mathrm{m}$.

the HmLAR2 expression pattern remained constant, in contrast to the expression of HmLAR1. In the periphery, HmLAR2 mRNA was detected exclusively in the paired Comb (C) cells. The $\mathrm{C}$ cells, like developing neurons, project long, growth cone-tipped processes. C cells could be labeled by in situ hybridization as early as E7, and expression persisted through E14 (Fig. 5F), the oldest stage at which HmLAR2 nucleic acid probes labeled effectively. 

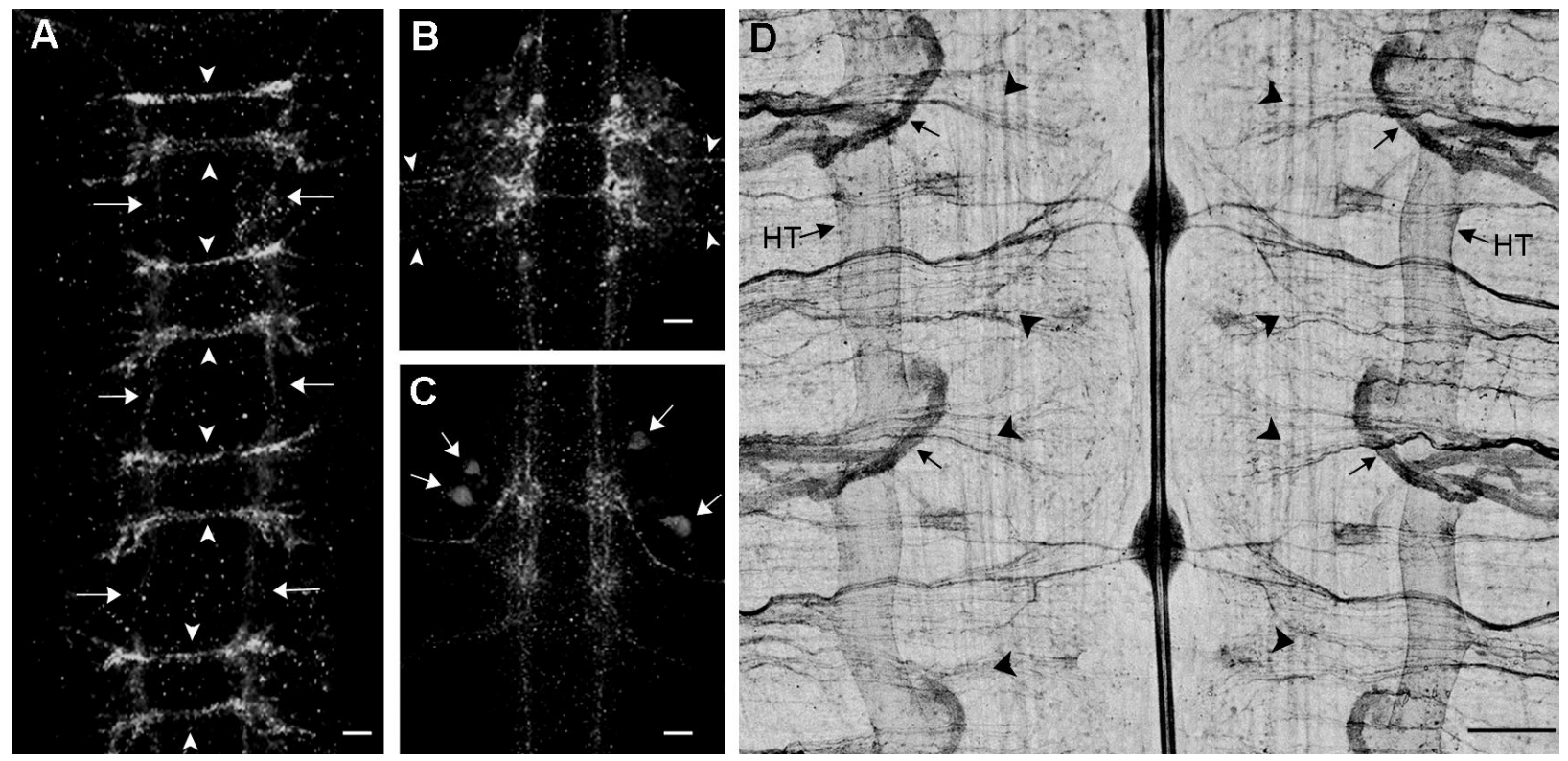

Figure 4. HmLAR1 immunoreactivity in the CNS and periphery. A, Immunofluorescent labeling of HmLAR1 in the four most anterior ganglia forming in an E7 animal. Note that HmLAR1 antisera did not label somata but strongly labeled fibers in the anterior and posterior commissures (arrowheads) and in the interganglionic connective nerves (arrows). B, HmLAR1 staining of an E11 segmental ganglion. Most staining was concentrated at the intersections of commissural and longitudinal fiber tracts. Labeled fibers, however, can also be clearly seen to enter or exit the ganglia through the anterior and posterior nerve roots (arrowheads). C, An E11 segmental ganglion after $24 \mathrm{hr}$ of treatment with brefeldin-A. Two bilateral neuronal cell bodies were prominently labeled in the dorsal anterior cell packet (arrows). D, HmLAR1 immunolabeling of two segments of an E14 embryo, visualized with peroxidase staining. Labeling can be seen in the fiber tracts of the two segmental ganglia, in the interganglionic and peripheral nerves, and on the lateral heart tubes $(H T)$, dorsoventral muscle fibers (arrowheads), and bilateral nephridial ducts (arrows). Anterior is up. Scale bars: $A-C, 10 \mu \mathrm{m} ; D, 200 \mu \mathrm{m}$.
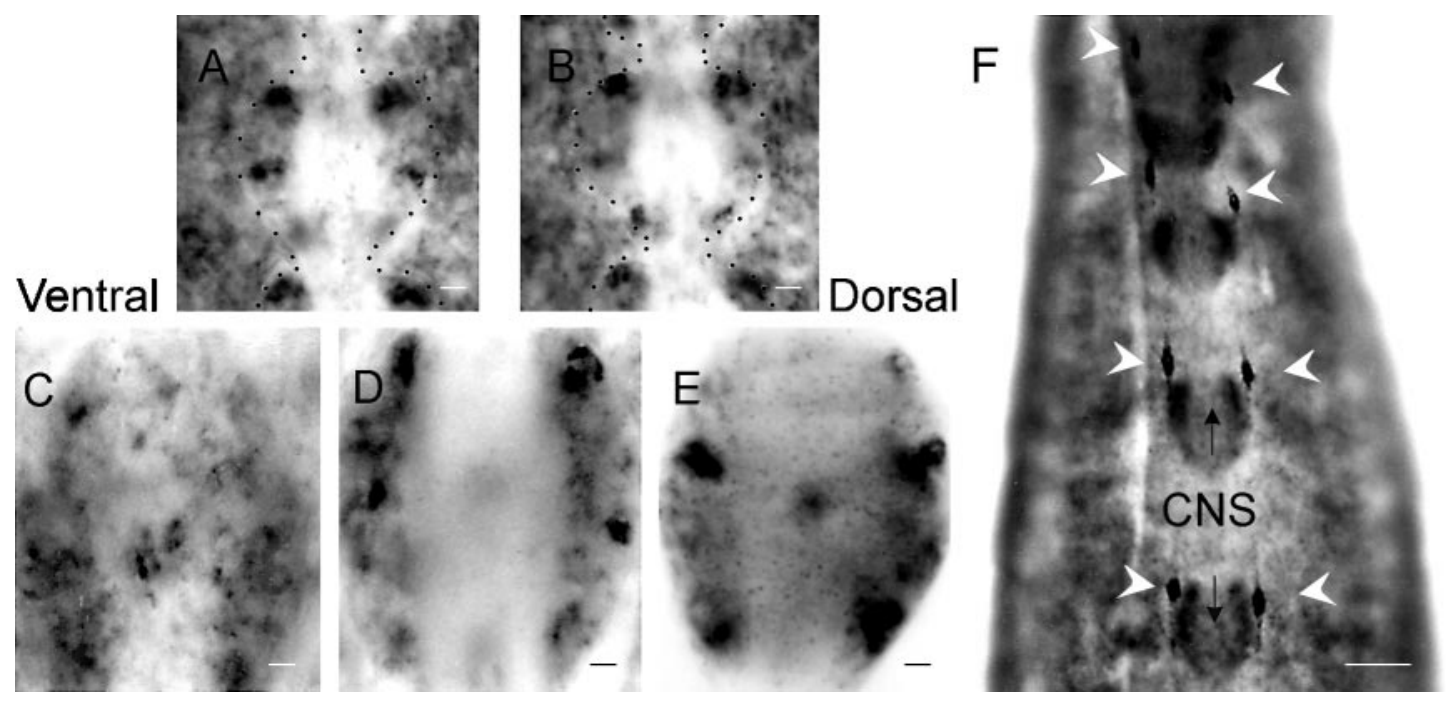

Figure 5. HmLAR2 mRNA is detectable by in situ hybridization in a small number of central neurons and in the Comb cells (no signal was observed from sense HmLAR2 probes; data not shown). $A, B$, At E7, HmLAR2 mRNA was expressed in three small clusters of central neurons in anterior midbody ganglia. $A$ shows a more ventral focal plane of this ganglion than does $B$, Dotted lines highlight the margins of the ganglion. $C-E$, At E14, HmLAR2 continued to be expressed by the same clusters of neurons at high levels, but at least one more cluster, as well as some cells expressing lower levels, could be detected. The panels progress from a more ventral $(C)$ to a more dorsal $(E)$ plane of focus through this midbody ganglion. $F, \mathrm{HmLAR} 2$ mRNA probes also labeled the paired Comb cells (white arrows) in the ventral body wall. Shown here are several anterior segments of an E14 embryo. Anterior is up. Scale bars: $A-E, 10 \mu \mathrm{m} ; F, 100 \mu \mathrm{m}$.

\section{Antibodies raised against HmLAR2 protein label somata in a pattern matching the mRNA expression pattern}

Antisera raised against a portion of the ectodomain of HmLAR2 heterologously expressed in bacteria labeled the same somata that the in situ hybridization probes representing the intracellular domain labeled. Antisera labeled the $\mathrm{C}$ cells and also labeled all the HmLAR2-expressing central neurons in their somata, although not all somata labeled at once at any stage (compare Figs. $5 A, B, 6 A ; 5 C-E, 6 F-H)$. 
Figure 6. HmLAR2 protein localization in the CNS as revealed by immunohistochemistry. $A$, Antibodies to HmLAR2-labeled cell bodies of two pairs of neurons (arrowheads) in this midbody ganglion from an E7 embryo are shown. These neurons correspond positionally with the most anterior and posterior pairs of neurons labeled by in situ hybridization (see Fig. 5). $B$, A more dorsal view of the same ganglion reveals more labeled processes. $C$, In E7 preparations processed for anti-HmLAR2 immunohistochemistry without Triton X-100 permeabilization, tracts of fibers were labeled, but somata were not. Shown here is an optical section through the neuropil of a midbody ganglion at approximately the same level shown in $A$. $D$, A more dorsal view of the ganglion shown in $C$ is given at approximately the same level shown in $B$. E, By E9, HmLAR2 protein was detected on neuronal processes exiting the CNS through the nerve roots (arrowheads) as well as on tracts in the neuropil and interganglionic connective nerves. This midbody ganglion was processed without Triton X-100 permeabilization. $F-H$, At E12, a subset of somata labeled by in situ hybridization with HmLAR2 probes was also labeled by anti-HmLAR2 immunohistochemistry (arrowheads). Panels progress from ventral $(F)$ to dorsal $(H)$. There was no time point in which somata of all neurons expressing HmLAR2 at high levels were simultaneously immunolabeled. To label somata, we permeabilized tissue with Triton $\mathrm{X}-100$. Note that the longitudinal tracts in the neuropil are strongly labeled and that somatic labeling, as expected, is cytoplasmic but not nuclear. Tracts in the roots were also strongly labeled but not in the focal planes shown. Anterior is up. Scale bars, $10 \mu \mathrm{m}$.
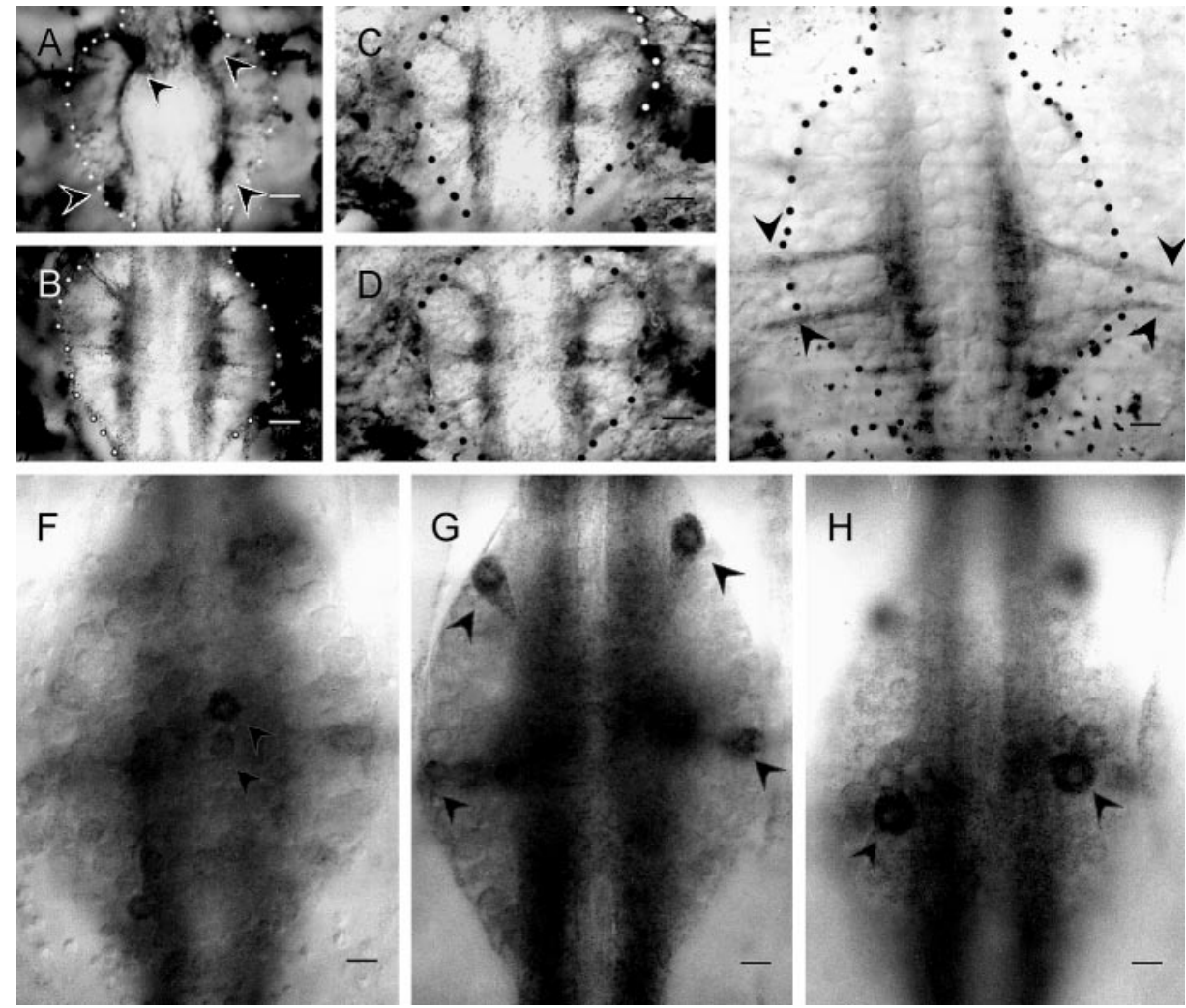

\section{HmLAR2 protein is also found along neurites in the CNS and periphery}

HmLAR2 protein was immunohistochemically detectable in segmental ganglia as early as E7. Antisera labeled an anterior and a posterior pair of cell bodies and also labeled processes (Fig. $6 A-D$ ). By E9 and even more by E12, the intensity of labeling in the neuropil had greatly increased and appeared somewhat diffuse (Fig. 6E-H), although in preparations labeled by HRPDAB staining, individual axons could be resolved as late as E12 (data not shown). By E9, neurites exiting the CNS through the roots were labeled (Fig. 6E) and could be followed into the periphery. In contrast to the pattern of HmLAR1 antisera labeling, at no stage did HmLAR2 antisera label processes traveling across ganglia along the commissures.

\section{Antisera to both HmLARs label some of the same peripheral axons}

At E14, many processes of central neurons were labeled intensely by either antisera and could be followed until their distal ends disappeared in the body wall (data not shown). Both antisera labeled processes extending along the heart tubes (Fig. 7A), in the sex nerve that links the fifth and sixth segmental ganglia to the male genitalia (Fig. 3D), and in the dorsal posterior root branch that is closely involved with the medial dorsoventral muscle. The labeling patterns observed either may result from cross-reactivity of the antisera in which only one of the HmLAR proteins is actually expressed or may represent colocalization of the two proteins.

Not unexpectedly, because of the high degree of sequence similarity between the intracellular phosphatase domains of HmLAR1 and HmLAR2, antisera raised against the HmLAR1 intracellular domain also labeled cells known to express HmLAR2 (data not shown). Additionally, the HmLAR1 ectodomain antisera weakly labels the HmLAR2-expressing Comb cells (see below), and the HmLAR2 ectodomain antisera weakly labels the HmLAR1-expressing heart tubes. It would therefore seem that a small degree of cross-reactivity exits between the antisera for the ectodomains of HmLAR1 and HmLAR2, although confirmation of this will require Western analysis.

\section{Immunohistochemistry indicates that one or both HmLARs are expressed by FMRFaminergic neurons that innervate the heart tubes and other peripheral targets}

The lateral heart tubes are known to be innervated by the HE and HA motor neurons that are known to express a FMRFamidelike neuropeptide (Kuhlman et al., 1985). The HEs are found in the third through 18th midbody segment of the leech, whereas the HAs are present only in the fifth and sixth segments. Antisera to either HmLAR ectodomain and to FMRFamide label the same neurites on the heart tubes (Fig. 7A,B). These neurites could be traced back to the CNS in anterior and posterior midbody seg- 

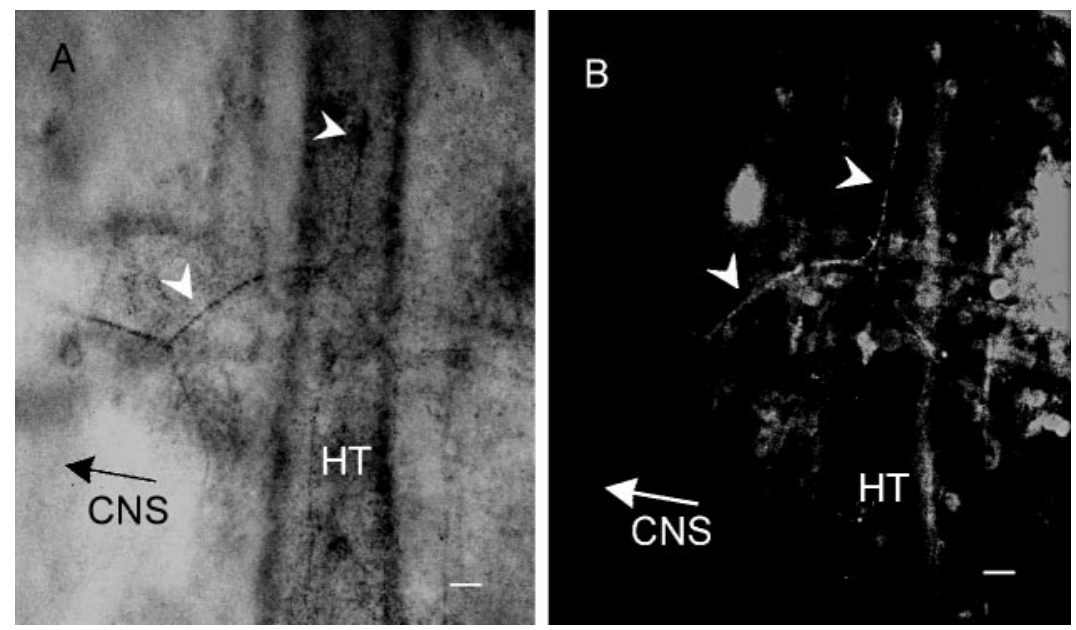

Figure 7. HmLAR2 antisera labeling peripheral processes of central neurons. $A$, Labeled by antisera raised against HmLAR2, an axon (arrowhead) from the 10th midbody ganglion of an E14 embryo could be followed from the CNS (data not shown) to the heart tube $(H T)$. HmLAR1 antisera similarly labeled axons innervating the heart tubes. $B$, Fluorescence image of the preparation shown in $A$, which was also processed with antisera for the neuropeptide FMRFamide and a fluorescent secondary, is shown. Note that the axon labeled in $A$ is labeled here as well (arrowheads). Anterior is $u p$. Scale bars, $10 \mu \mathrm{m}$.

ments, indicating that they are probably the axons of the HE neurons and possibly also the HAs. In situ hybridization with HmLAR1 probes, combined with intracellular dye injection of the HEs to confirm cellular identity, failed to demonstrate HmLAR1 mRNA at detectable levels in the HE, whereas the somata of HE neurons did not label with HmLAR2 antisera (data not shown). The lack of somatic labeling by the antisera does not eliminate the possibility that the HEs express HmLAR2, however. Moreover, in situ hybridization with HmLAR2 probes weakly labeled many cells, possibly including the HEs. Thus, the labeling observed may be attributable to HmLAR2 on the HE axons or to either HmLAR expressed by previously unidentified heart neurons.

In addition to the axons on the heart tubes, fibers that extended along peripheral nerves and then branched out into the dorsal body wall were also labeled with both antisera. Although the HE neurons have supernumerary processes at E14 (Jellies et al., 1992), some of these processes were clearly outside of the field of $\mathrm{HE}$ innervation. Thus, in addition to the HEs, other cells labeled by HmLAR antisera were also FMRFaminergic. In addition, spindle-shaped cryptolarval cells were labeled by both HmLAR2 and FMRFamide antisera (data not shown). In situ hybridization confirmed that both HmLARs were expressed by cryptolarval cells. The immunolabeled cells extended fine processes and in their morphology and irregular arrangement resembled neurons growing in cell culture. Their morphologies together with their FMRF expression suggest that they are likely to be neuronal cells.

\section{HmLAR2 protein is expressed by C cells as early as $E 7$, but it appears on the cell surface only when process extension begins}

As early as E7, C cells along the full length of the embryo were labeled by HmLAR2 ectodomain antisera (Fig. 8A,B). Even the less developed, more posterior $C$ cells, which had not yet achieved the bipolar organization from which fine processes emerge, were labeled (Fig. 8A) in preparations that were permeabilized with detergent before applying the primary antibody. In unpermeabilized E7 preparations, in contrast, antisera to HmLAR2 labeled fibers of the central neurons (Fig. $6 C, D$ ) but did not label the $\mathrm{C}$ cells. Thus, at E7, detectable levels of HmLAR2 are present on the cell surface of central neurons, whereas the level of HmLAR2 on the surface of the $\mathrm{C}$ cell is below the limits of detection.

Between E7 and E8, C cells begin to elaborate fine processes in an anterior to posterior succession (Jellies and Kristan, 1988).
The $\mathrm{C}$ cell processes that have emerged are in a period of slow extension (Jellies and Kristan, 1988). In unpermeabilized E7 and E8 embryos, antibodies to HmLAR2 ectodomain labeled the exterior surfaces of those $\mathrm{C}$ cells that displayed the beginnings of processes (data not shown). By E9, when all $\mathrm{C}$ cells have elaborated processes and the $\mathrm{C}$ cells begin a period of rapid process extension (Jellies and Kristan, 1988), HmLAR2 protein was detected on growth cones, along processes, and on the somata of all $\mathrm{C}$ cells in unpermeabilized embryos (Fig. 8D). The ability of the antisera to detect HmLAR2 on the surface of a specific $\mathrm{C}$ cell in unpermeabilized preparations thus corresponds well with the time at which that cell begins to extend processes.

\section{Throughout process extension, HmLAR2 protein is found on $\mathbf{C}$ cell processes, growth cones, and filopodia}

From late E7 through E14, the latest stage assayed, HmLAR2 antisera label processes of the C cells (Fig. $8 B-F$ ). In addition, growth cones were clearly labeled in permeabilized preparations by E11 (Fig. $8 E$ ). Labeled filopodia were discernible by E12 and continued to be labeled at E14 (Fig. $8 F$ ). Interestingly, HmLAR2 antisera revealed the presence of fine filopodia-like projections extending from the shafts of the $\mathrm{C}$ cell processes (Fig. $8 F$ ).

\section{DISCUSSION}

\section{Why two HmLARs?}

Leeches, like mammals, have multiple LAR homologs, whereas Drosophila seems to have only one. The sequence homologies between HmLAR1, HmLAR2, Drosophila LAR (DLAR), rat LAR, and rat PTP NE-3 suggest that the two leech homologs arose from an independent gene duplication after the divergence of insects and annelids. That independently occurring gene duplications among mammals and annelids should give rise to similar variations of the LAR theme suggests that such variations offer a specific functional advantage.

One potential benefit of having two closely related CAM-like ectodomains is the possibility of specific heterophilic interactions. Such interactions could occur where processes of central neurons bearing either HmLAR1, HmLAR2, or both appear to come into contact with the HmLAR1-expressing target cells of the heart tube and dorsoventral muscles. In this respect, it will be of great interest to determine whether the extracellular domains of 

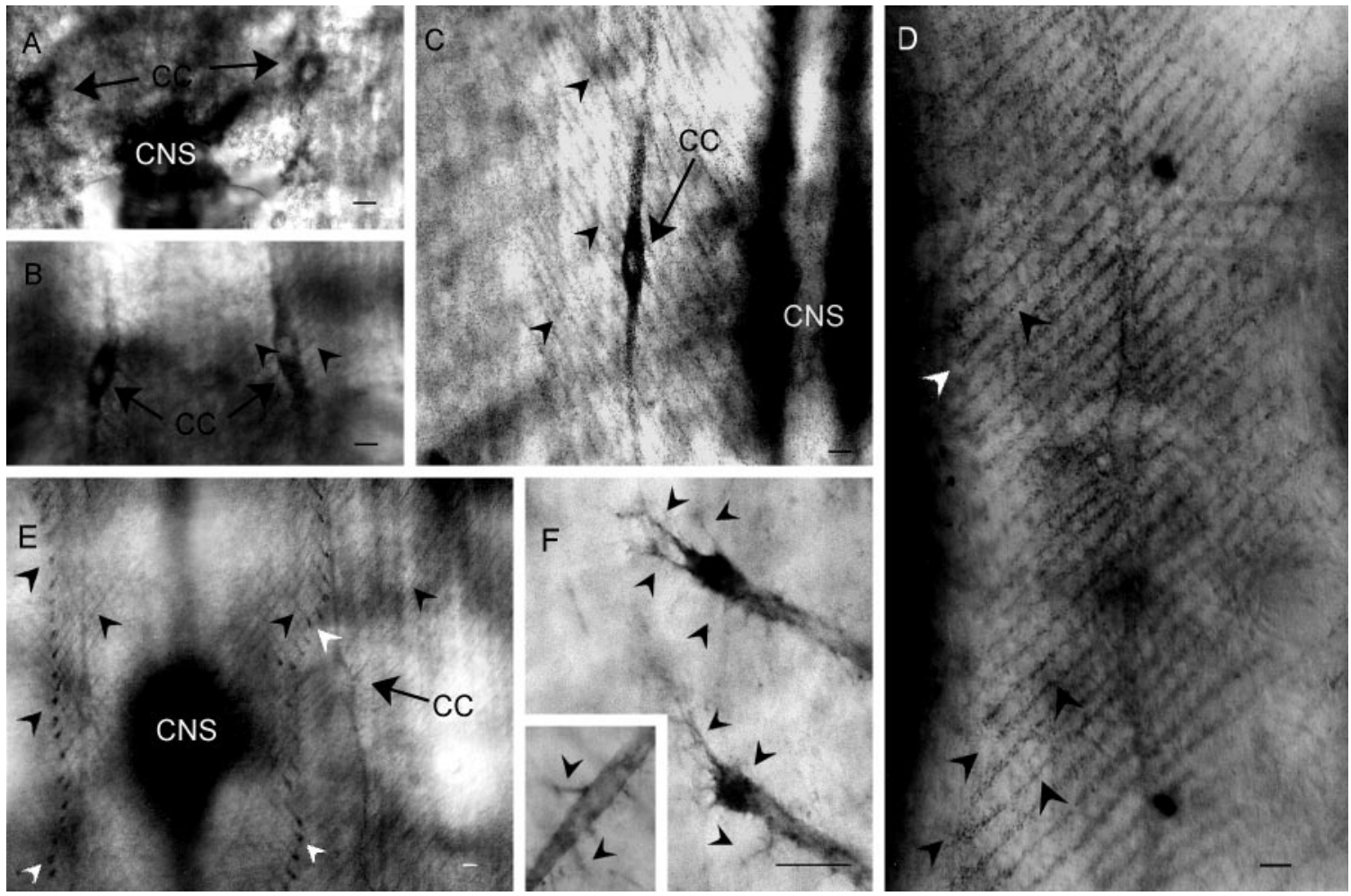

Figure 8. HmLAR2 protein can be observed in the Comb cells, in the Comb cell processes, and in their growth cones. $A$, Comb cells $(C C)$ from the 15th midbody segment of an E7 embryo were labeled by antisera raised against HmLAR2. Labeling was perinuclear, and no fine processes can be seen. $B$, More developed $C C$ from the fourth midbody segment of the same preparation shown in $A$ were also labeled by HmLAR2 antisera. These more mature cells have elaborated short, fine processes in which HmLAR2 was detected (arrowheads). $C$, At E9, HmLAR2 antisera continued to label the $C C$ body, and fine processes (arrowheads) were more easily discerned. Growth cones are labeled lightly, at approximately the same intensity that processes are labeled. $D$, In an unpermeabilized E9 preparation, HmLAR2 antibodies can be observed to label the surface of a Comb cell. Labeling is excluded from the cytoplasm, indicating that only extracellular proteins were available to the primary antibody. Both processes (black arrowheads) and growth cones (white arrowhead) were also labeled. E, At E11, HmLAR2 antisera labeled somata (CC), processes (black arrowheads), and growth cones (white arrowheads) of the Comb cells. Growth cones marked by white arrowheads are on processes extending posteriorly and across the ventral midline from contralateral Comb cells. Note that at this stage the growth cones label more strongly than do the processes they lead. F, At E14, HmLAR2 antibody labeling could be resolved on filopodia (arrowheads) extending from Comb cell growth cones (black arrowheads). Additionally, HmLAR2 antibodies also labeled fine, filopodia-like extensions that emanated from the shafts of the Comb cell processes. Anterior is up. Scale bars, $10 \mu \mathrm{m}$.

HmLAR1 and HmLAR2 adhere specifically to each other. In the chick, the ectodomain of the CAM-like $\operatorname{rPTP}-\beta$ is actually a signaling molecule and the ligand of the CAM-like protein contactin (Peles et al., 1995). Similarly, the two HmLARs may be able to function as mutual ligands and receptors.

\section{The timing of HmLAR mRNA expression and the protein distribution in neurons and $\mathbf{C}$ cells suggest that both HmLARs participate in pathfinding}

The timing of expression of the two HmLARs by neurons and of the apparent externalization of HmLAR2 by C cells suggests that these proteins play a role in process outgrowth. The earliest expression of the HmLARs in the CNS occurs just as the small subset of neurons that are "pioneers" are growing into the periphery (Gan and Macagno, 1995) and interneuronal connections are first being established. Although the $\mathrm{C}$ cells are also making HmLAR2 message and protein at this time, they do not express the protein on the cell surface until after process outgrowth begins. Furthermore, as development proceeds, the number of HmLAR1-expressing central neurons increases at approximately the same time that the relatively large subset of neurons that follow the pioneers are extending projections into peripheral regions (Gan and Macagno, 1995). Later in development,
HmLAR1 is expressed by the later-appearing peripheral sensory neurons at the time these cells extend projections toward the CNS (Stewart et al., 1985). Neurite outgrowth and HmLAR1 and HmLAR2 expression thus occur contemporaneously, as would be expected if these proteins were involved in some aspect of pathfinding.

The localization of both HmLARs on processes is also consistent with a role in pathfinding. Although the growth cones on the HmLAR-expressing neurons were difficult to observe, the growth cones of the $\mathrm{C}$ cells were easily resolved in situ. Stoker et al. (1995) observed that CRYP- $\alpha$, a chicken LAR homolog, is present on growth cones of neurons growing in culture. HmLAR2 is present on growth cones from early process extension onward, although it is more easily visualized in preparations older than E10. HmLAR2 is clearly present on filopodia, as would be expected if it participates in directing outgrowth.

\section{HmLAR expression and pathway choice in the CNS}

Although both HmLARs are present along processes of central neurons in the CNS and periphery, there is a clear difference in the pattern of HmLAR1- and HmLAR2-bearing axons. Although processes in both the anterior and posterior ganglionic 
commissures labeled with HmLAR1 antisera, HmLAR2 antisera never labeled commissural processes. The lack of labeling in the commissures is unlikely to be caused by a failure of the antisera to detect HmLAR2 protein at this location, because the sera are sensitive enough to label such fine structures as filopodia. Rather, these findings suggest distinct, opposing, anatomical correlates specific to HmLAR1 and HmLAR2 expression. It will be of interest to test the possibility that the HmLARs may function in guiding axons toward or away from the commissures.

\section{A different role for HmLAR1 on muscle cells}

Both HmLARs, unlike DLAR (Tian et al., 1991), are expressed outside the CNS. Unlike HmLAR2, HmLAR1 is expressed by peripheral muscle cells in the heart tubes, dorsoventral muscles, male organ, and head and tail suckers. These cells do not extend long processes and most likely use HmLAR1 for functions other than navigation. Because axons bearing one or both HmLARs innervate these muscles, we hypothesize that HmLAR1 on muscles may play a role in target recognition.

Zhang and Longo (1995) found that a secreted form of LAR is made in mice neuromuscular tissues by splicing in-frame stop codons into the extracellular domain. Interestingly, the extracellular domain of HmLAR1 was detected at higher levels in peripheral cells when protein secretion was blocked. That HmLAR1 extracellular domain may function as a diffusible ligand is an exciting possibility to be considered in the future.

\section{Conclusions}

We have found two leech rPTPs, HmLAR1 and HmLAR2, expressed by different subsets of central neurons, peripheral neurons, and non-neuronal cells. Central neurons begin to express the HmLARs at approximately the same time that axonogenesis begins. Both HmLARs are localized on axons, and HmLAR2 is found on the growth cones and filopodia of the neuron-like Comb cells. The timing of HmLAR expression and the protein localization suggest that these proteins play a role in directing neurite outgrowth. Such a role has been proposed for LAR homologs in other species and has been established for DLAR (Desai et al., 1996, 1997).

Although no ligands have been identified, the structure of the HmLARs suggests that they are receptors. Using antibodies to the ectodomains of HmLARs, we have tested the ability of these proteins to act as receptors controlling the direction of outgrowth in response to extracellular cues. Results from these experiments (Gershon et al., 1998) (M. W. Baker, T. R. Gershon, and E. R. Macagno, unpublished observations) support the hypothesis that the HmLARs can function as guidance cue receptors.

HmLAR1 expressed by muscle cells is likely to serve a different function. The HmLAR1-expressing muscle cells are innervated by central neurons, including neurons expressing HmLAR1 or HmLAR2. We hypothesize that HmLAR1 on peripheral cells may act as a ligand for a neuronal receptor, possibly one of the HmLARs. The roles of ligand and receptor are not necessarily mutually exclusive, and heterophilic binding of two HmLARs or homophilic binding between neuronal and non-neuronal HmLAR1 would allow for two-way communication that could be critical for the development of normal innervation.

\section{REFERENCES}

Ausubel F, Brent R, Kingston R, Moore D, Seidman JG, Smith J, Struhl $\mathrm{K}$, eds (1995) Current protocols in molecular biology. New York: Wiley.

Bodden K, Bixby JL (1996) CRYP-2: a receptor-type tyrosine phos- phatase selectively expressed by developing vertebrate neurons. J Neurobiol 31:309-324.

Brady-Kalnay SM, Flint AJ, Tonks NK (1993) Homophilic binding of PTP $\mathrm{mu}$, a receptor-type protein tyrosine phosphatase, can mediate cell-cell aggregation. J Cell Biol 122:961-972.

Chiba A, Keshishian H (1995) Neuronal pathfinding and recognition: roles of cell adhesion molecules. Dev Biol 180:424-432.

Colamarino SA, Tessier-Lavigne M (1995) The axonal chemoattractant netrin-1 is also a chemorepellent for trochlear motor axons. Cell 81:621-629.

Desai CJ, Gindhart JG, Goldstein LSB, Zinn K (1996) Receptor tyrosine phosphatases are required for motor axon guidance in the Drosophila embryo. Cell 84:599-609.

Desai CJ, Krueger NX, Saito H, Zinn K (1997) Competition and cooperation among receptor tyrosine phophatases control motor neuron growth cone guidance in Drosophila. Development 124:1941-1951.

Gan WB, Macagno ER (1995) Developing neurons use a pioneer's peripheral arbor to establish their terminal fields. J Neurosci 15:3254-3262.

Gershon TR, Baker MW, Nitabach M, Macagno ER (1998) The leech protein tyrosine phosphatase HmLAR2 is concentrated in growth cones and is involved in process outgrowth. Development, in press.

Harlow E, Lane D (1988) Antibodies: a laboratory manual. Cold Spring Harbor, NY: Cold Spring Harbor Laboratory.

Jellies J, Kristan WB (1988) Embryonic assembly of a complex muscle is directed by a single identified cell in the medicinal leech. J Neurosci 8:3317-3326.

Jellies J, Kopp DM, Bledsoe JW (1992) Development of segment- and target-related neuronal identity in the leech. J Exp Biol 170:71-92.

Kornblihtt AR, Umezawa K, Vibe-Pedersen K, Baralle FE (1985) Primary structure of human fibronectin: differential splicing may generate at least 10 polypeptides from a single gene. EMBO J 4:1755-1759.

Krueger N, Streuli M, Saito H (1990) Structural diversity and evolution of human receptor-like protein tyrosine phosphatases. EMBO J 9:3241-3252.

Krueger N, Van Vactor D, Wan H, Gelbart W, Goodman CS, Saito H (1996) The transmembrane tyrosine phosphatase DLAR controls motor axon guidance in Drosophila. Cell 84:611-622.

Kuhlman JR, Li C, Calabrese R (1985) FMRF-amide-like substances in the leech. J Neurosci 5:2301-2309.

Nardelli-Haefliger D, Shankland M (1992) Lox2, a putative leech segmental identity gene, is expressed in the same segmental domain in different stem cell lineages. Development 116:697-710.

Nitabach MN (1995) Expression of protein kinases and protein phosphatases in the nervous system of the embryonic leech. PhD thesis, Columbia University.

Peles E, Nativ M, Campbell PL, Sakurai T, Martinez R, Lev S, Clary DO, Schilling J, Barnea GD, Plowman GD, Grumet M, Schlessinger J (1995) The carbonic anhydrase domain of receptor tyrosine phosphatase $\mathrm{B}$ is a functional ligand for the axonal cell recognition molecule contactin. Cell 82:251-260.

Sap J, Jiang YP, Friedlander D, Grumet M, Schlessinger J (1994) Receptor tyrosine phosphatase R-PTP-kappa mediates homophilic binding. Mol Cell Biol 14:1-9.

Sawyer RT (1986) Leech biology and behavior. Oxford: Oxford UP.

Serafini T, Kennedy TE, Galko MJ, Mirzayan C, Jessell TM, TessierLavigne M (1994) The netrins define a family of axon outgrowthpromoting proteins homologous to C. elegans UNC-6. Cell 78:409-424.

Stewart RR, Macagno ER, Zipser B (1985) The embryonic development of peripheral neurons in the body wall of the leech Haemopis marmorata. Brain Res 332:150-157.

Stoeckli ET, Sonderegger P, Pollerberg GE, Landmesser LT (1997) Interference with axonin-1 and Nr-CAM interactions unmasks a floorplate activity inhibitory for commissural axons. Neuron 18:209-221.

Stoker A, Gehrig B, Haj F, Bay B-H (1995) Axonal localisation of the CAM-like tyrosine phosphatase CRYP- $\alpha$ : a signalling molecule of embryonic growth cones. Development 121:1833-1844.

Streuli M, Krueger N, Tsai A, Saito H (1989) A family of receptor-linked protein tyrosine phosphatases in humans and Drosophila. Proc Natl Acad Sci USA 86:8698-8702.

Studier FW, Rosenberg AH, Dunn JJ, Dubendorff JW (1990) Use of T7 RNA polymerase to direct expression of cloned genes. Methods Enzymol 185:60-89.

Swofford DL (1994) PAUP-phylogenetic analysis using Parsimony, version 3.1.1. Champaign, IL: Illinois Natural History Survey. 
Tessier-Lavigne M (1995) Eph receptor tyrosine kinases, axon repulsion, and the development of topographic maps. Cell 82:345-348.

Tian SS, Tsoulfas P, Zinn K (1991) Three receptor-linked proteintyrosine phosphatases are selectively expressed on central nervous system axons in the Drosophila embryo. Cell 67:675-680.

Vaney DI (1992) Photochromic intensification of diaminobenzidine reaction product in the presence of tetrazolium salts: applications for intracellular labeling and immunohistochemistry. J Neurosci Methods 44:217-223.

Walton KM, Martell KJ, Kwak SP, Dixon JE, Largent BL (1993) A novel receptor-type protein tyrosine phosphatase is expressed during neurogenesis in the olfactory neuroepithelium. Neuron 11:387-400.

Wu DY, Goldberg DJ (1993) Regulation of tyrosine phosphorylation at the tips of growth cone filopodia. J Cell Biol 123:653-664.

Yang T, Xie YM, Yeo T, Longo FM (1997) LAR tyrosine phosphatase receptor deficient neurons: decreased response to neurotrophins. Soc Neurosci Abstr 23:1434

Yeo TT, Yang T, Massa SM, Zhang JS, Honkaniemi J, Butcher LL, Longo FM (1997) Deficient LAR expression decreases basal forebrain cholinergic neuronal size and hippocampal cholinergic innervation. J Neurosci Res 47:348-360.

Zhang JS, Long FM (1995) LAR tyrosine phosphatase receptor: alternative splicing is preferential to the nervous system, coordinated with cell growth and generates novel isoforms containing extensive CAG repeats. J Cell Biol 128:415-431.

Zheng JQ, Wan JJ, Poo MM (1994) Turning of nerve growth cones induced by neurotransmitters. Nature 368:140-144. 